\title{
THE DEVELOPMENTAL STAGES OF NAUPLIUS LARVAE OF PAREUCHAETA RUSSELLI (FARRAN)*
}

\author{
Fumihiko KogA** \\ (Received May 26, 1960)
}

The pelagic copepoda are small crustacean averaging in size less than five millimeters, whose abundance is a measure of their importance as a direct source of food supply for the young of the commercial fishes. Their nauplius larvae are so abundant that they play an important rôle in the economy of the sea. It is ardently necessary to study further on life history of the important species among the copepoda found in the waters surrounding Japan. But owing to the fact that the nauplius larvae are very small in size and differ in shape from that of adult, the nauplii have been remained for a long time untouched. The nauplius stages of Euchaeta have been described by CAmpbell (1934) ${ }^{1}$ ) and Nicholls $\left.(1934)^{5}\right)$. The present paper deals with the larval development of $P$. russelli (F ARRAN). The species $(3.14-4.06 \mathrm{~mm}$.) is one of large copepoda. FarRAN (1936) ${ }^{2}$ described the species from the Great Barier Reef under the name Euchaeta russelli (GIESBRECHT). MoRI $(1936)^{4}$ recorded the occurrence of Euchaeata flava Gresbrecht from the neighbouring waters of Japan. But Mori's specimen is, as pointed out by TANaKa $(1957)^{6}$, identical with Pareuchaeta russelli (FARRAN). The species is common in the warm waters of Japan, and has been also recorded from Indian and Pacific Oceans.

The author wishes to thank Dr. O. TANAKA, the Director of the Fishery Research Laboratory of Kyushu University, for final critism and suggestions, Mr. S. SueHIRo and $\mathrm{Mr}$. T. SAWADA for laboratory facilities.

\section{Materials and Methods}

The adult female specimens of $P$. russelli were obtained from the region off Tsuyazaki, north-western Coast of Kyushu, where the warm Tsushima-current prevails, by vertical hauls of a Norpac-type plankton net designed for collecting macroplankton. The net is made of bolting silk GG-54 (mesh aperture approx. $0.33 \mathrm{~mm}$.), the conical straining section measuring $180 \mathrm{~cm}$. in lateral length, the mouth diameter is $45 \mathrm{~cm}$.. $P$. russelli spawns in the north-western area of Kyushu from summer to early winter. The female carrying a egg-sac was immediately removed after gathering, and placed in the rearing jars filled with the water $\left(\mathrm{Cl}^{-}, 18.8 \%\right)$. The temperature $\left(16.6^{\circ} \mathrm{C}-\right.$ $17.8^{\circ} \mathrm{C}$ ) of the jars was kept constant by running water surrounding the jars. As a

* Contribution from the Fishery Research Laboratory, Kyushu University.

** The Department of Fisheries, Faculty of Agriculțure, Kyushu University. 
food Skeletonema costatum (GREviLle) was added in rearing jars, but there was no indication that the larvae fed upon it.

\section{Egg and Breeding}

The number of eggs produced by a female per brood ranged from 17 to 22 , with an average of 19.9 eggs. The number of eggs produced under starved condition decreased to about 2-3 eggs per sac. Marshall and ORR (1955) ${ }^{3)}$ gave a full details of the effect of various kinds of food on spawning of Calanus. According to Nicholls $\left.(1934)^{5}\right)$ the number of eggs in one sac produced by Euchaeta norvegica BoEck was usually about 50. About a week after spawning the sac is thrown off and another batch may appear within 8 days.

The subspherical egg of Pareuchaeta russelli is $0.29 \mathrm{~mm}$. in diameter. The egg of Euchaeta norvegica is according to Nicholls measured $0.4 \mathrm{~mm}$. in diameter. The egg in the sac is bluish green in colour. As development proceeds the bluish green colour disappears. After 5-6 days, the abundant red oil-globules in the posterior region of the body give the embryo a reddish tinge. According to Campbell (1934) ${ }^{1}$ Euchaeta japonica Marukawa retains blue colour of eggs till the Nauplius I. The hatching usually occurs within several hours after sunset. As soon as the nauplii burst out they were removed from their parent which feed upon them.

\section{Nauplius larvae}

A large number of nauplii were reared in the laboratory in December, 1958. The Nauplius I which hatched out at $8 \mathrm{p} . \mathrm{m}$. on December $5 \mathrm{th}$, is $0.41 \mathrm{~mm}$. in the average length. Within 10 hours the specimen moults and develops into the next stage; the Nauplius II which has an average length of $0.42 \mathrm{~mm}$.. Succeeding moults follow one another at every intervals of approximate 12 hours. The Nauplius III measures $0.44 \mathrm{~mm}$.; the Nauplius IV $0.48 \mathrm{~mm}$; the Nauplius V $0.52 \mathrm{~mm}$.; and the Nauplius VI $0.57 \mathrm{~mm}$.

Viewed ventrally the Nauplius I is broadly oval, and slightly pointed anteriorly and quite rounded posteriorly; there are no hairs on the posterior end. In the succeeding stages the body assumes a more elongate form; ovoid in the Nauplius III and pyriform in the Nauplius VI owing to elongation of the posterior half. The abdomen does not definitely differentiate from the thorax until quite late in the developmental stages of nauplius.

The nauplius larvae retained reddish tinge in the posterior region of the body by the reddish oil-globules of various sizes. A small eye-spot is present in all stages. The gnathobase is represented by a slight protuberance on the mandibular coxa as the nauplius is fed by the plentiful supply of yolk. A slight indication of the rostrum can first be seen in the Nauplius III, but in Euchaeta norvegica it first is seen in the Nauplius IV.

One pair of feelers appears on the posterior margin of the body in the Nauplius 
II. The feelers are about as long as or a little longer than the body. They are kept until the Nauplius VI, in which another two pairs of short ones appear. The feelers

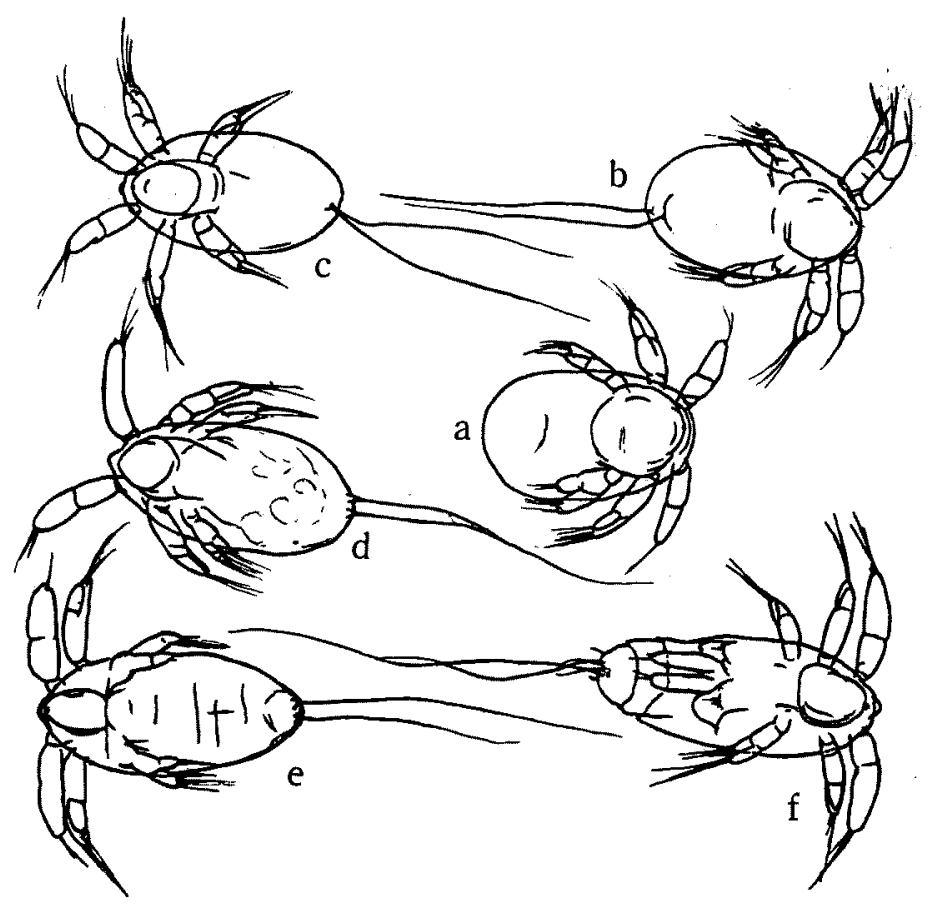

Fig. 1. Development of nauplius of Pareuchaeta russelli (FARRAN) a-f, nauplius stage I to VI, ventral view. $(\times 50)$

of Euchaeta norvegica and Pareuchaeta russelli are very similar in structure. The feelers of Euchaeta japonica appear in the Nauplius II, the another two short hairs appear also in this stage and persist to the Nauplius VI.

The nauplii have three pairs of cephalic appendages. These appendages are small in comparison with the size of the body. The labrum surrounded by these appendages is conspicuous when viewed from the ventral. The antennule (Fig. 2, $a-f$ ) is composed of three segments in each stage. The antenna (Fig. 2, g-1) consists of a coxa, basipodite, unsegmented endopodite and segmented exopodite; the coxa lacks armature. In the maxillule (Fig. 2, s) the inner lobe bears three short terminal setae and a number of setae on inner margin; the outer lobe of exopodite bears six setae. The maxilla (Fig. 2, $t$ ) is imperfectly divided into lobes, but it is difficult to distinguish the number of setae furnished on the lobes. The maxilliped (Fig. 2, $\mathfrak{u}$ ) is an elongated lobe with two large terminal setae. The first leg (Fig. 2, v) is not yet differentiated; there are three satae on each end of the endopodite and exopodite. The second leg (Fig. 2, w) is an appendage similar in shape to the first leg, the endopodite bears only two setae.

24-30 hours elapse before the final nauplius moults and develops into the Copepo- 


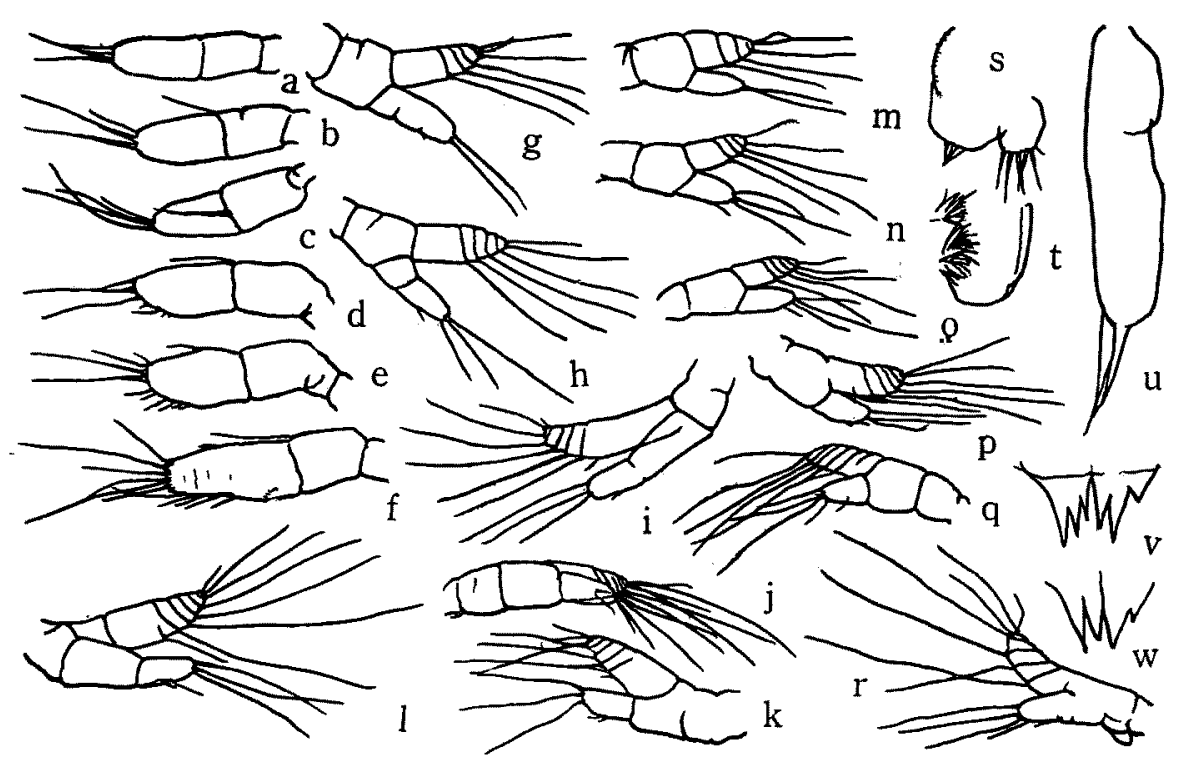

Fig. 2. Development of appendages of Pareuchaeta russelli (FARRAN)

$\mathrm{a}, \mathrm{g}$ and $\mathrm{m}$, nauplius stage-I antennule, antenna and mandible,

$\mathrm{b}, \mathrm{h}$ and $\mathrm{n}$, nauplius stage--II antennule, antenna and mandible,

$c$, $i$ and $o$, nauplius stage-III antennule, antenna and mandible,

$d, j$ and $p$, nauplius stage-IV antennule, antenna and mandible,

$\mathrm{e}, \mathrm{k}$ and $\mathrm{q}$, nauplius stage $-\mathrm{V}$ antennule, antenna and mandible,

$f, 1, r, s, t, u, v$ and $w$, nauplius stage-VI antennule, antenna, mandible, maxillule, maxilla, maxilliped, first leg and second leg.

$$
\text { a-r }(\times 110), \text { s-w }(\times 230)
$$

dite $\mathrm{I}$, and this period appears to be the critical causing a striking change in the development of $P$. russelli: the animal increases in length by more than one and half the last nauplius. All of the cephalic appendages and two pairs of thorasic appendages are present. Almost all of the larvae survived to the Copepodite I.

\section{Summary}

1. Pareuchaeta russelli is one of the common species in the warm waters of Japan.

2. The eggs are carried in the egg-sac attached to the genital pore until they are hatched.

3. The subspherical egg of $P$. russelli is measured $0.29 \mathrm{~mm}$. in diameter. The number of eggs in one sac is usually about 20 . The sac is thrown off after spawning and within 8 days the next batch may appear.

4. The eggs in sac and in ovary are bright bluish green in colour, but the red oil-globules give the embryo a reddish tinge at time they emerge.

5. It appears that $P$. russelli passes through its nauplius stages without feeding. because it has the plentiful supply of yolk to pass through its nauplius stages. 
6. There are six nauplius stages. The total durration of the nauplius stage was usually about 4 days.

7. 24-30 hours elapse before the final nauplius moults and develops into the Copepodite I, and this period appears to be most critical in the development.

\section{References}

1) Campbell, M. H.: J. Biol. Boad. Canada, (1), 1-65 (1934).

2) Farran, G. P.: Copepoda. Greast Barrier Reef Expedition, 1928-29. Sci. Repts., 5 (3), 73142 (1936).

3) MARshall, S. M. and A. P. ORR,: Biology of a marine copepod. (1955).

4) MORI, T.: The pelagic copepoda from the neighbouring waters of Japan. (1936),

5) Nicholls. A.G.: Proc. Roy. Soc. Edinb. 54 pt. 1 (4), 31-55 1934).

6) TANAKA, O.: Zooplankton in the warm Tsushima-current. The pelagic copepoda in the Japan Sea-1. (1957). (in Japanese). 